\title{
BMJ Open Perceived quality of surgical care in association with patient-related factors and correlation to reported postoperative complications in Finland: a cross-sectional study
}

Ira Helena Saarinen (D , ,,2 Jaana-Maija Koivisto, ${ }^{2,3}$ Antti Kaipia, ${ }^{2,4}$ Elina Haavisto ${ }^{2,3}$

To cite: Saarinen IH, Koivisto JM, Kaipia A, et al. Perceived quality of surgical care in association with patientrelated factors and correlation to reported postoperative complications in Finland: a cross-sectional study. BMJ Open 2020;10:e037708. doi:10.1136/ bmjopen-2020-037708

- Prepublication history for this paper is available online. To view these files, please visit the journal online (http://dx.doi. org/10.1136/bmjopen-2020037708).

IHS and J-MK contributed equally.

Received 13 February 2020 Revised 14 October 2020 Accepted 20 0ctober 2020

Check for updates

(c) Author(s) (or their employer(s)) 2020. Re-use permitted under CC BY-NC. No commercial re-use. See rights and permissions. Published by BMJ.

${ }^{1}$ Surgery, Etelä-Pohjanmaan sairaanhoitopiiri, Seinajoki, Finland

${ }^{2}$ Surgery, Satakunnan sairaanhoitopiiri, Pori, Finland ${ }^{3}$ Nursing Science, Turun Yliopisto, Turku, Finland ${ }^{4}$ Urology, Tampere University, Tampere, Finland

Correspondence to Dr Ira Helena Saarinen; Ira.saarinen@gmail.com

\section{ABSTRACT}

Objective To study if patient-related factors are associated with patient-evaluated quality of care in surgery. To examine if there is an association with postoperative complications and patient-evaluated low quality of care.

Design A correlation cross-sectional study, in addition, a phone call interview at 30 days postoperatively to examine complications.

Setting The data on patients admitted for non-cardiac general and orthopaedic surgery at a central hospital in Southwestern Finland were collected in two phases during an 8-month period.

Participants 436 consecutive consenting and eligible in-ward non-cardiac general surgery and orthopaedic surgery adult patients. Ambulatory, paediatric and memory disorder patients were excluded. 378 patients completed the questionnaire (Good Nursing Care Scale for Patients (GNCS-P)).

Methods Perceived quality of care was examined by the GNCS-P questionnaire. Patient-related factors were obtained from electronic patient records and questionnaire. A telephone interview related to postdischarge complications was conducted 30 days after discharge.

Main outcome measures Patient evaluation of quality of care at discharge, its association with patient-related factors and patient-reported postdischarge complications. Results The overall quality was evaluated high or very high by the patients. The lowest overall quality of care rate was assessed by surgical patients living alone $(p=0.0088)$ and patients who evaluated their state of health moderate or poor $(p=0.0047)$. Surgical patients reporting postoperative complications after discharge evaluated lower overall quality of care $(p=0.0105)$ than patients with no complications.

Conclusion Patient demographic factors do not seem to influence the perceptions of the quality of care. Instead, subjective state of health and living conditions (living alone) may have an influence on the patient experience of quality of care. The perceived quality of care in healthcare staff technical and communication skills may have an association with reported postoperative complications.
Strengths and limitations of this study

- The strength of the study resides in different disciplines of surgical patients during a long period (8months).

- The study population was demographically and geographically confined and the variability in quality evaluation was rather low.

- Perceived quality of care was examined by a validated questionnaire (Good Nursing Care Scale for Patients) at discharge, patient-related risk factors were obtained from patient records and complications were determined by a follow-up telephone call at 30 days postdischarge.

- This study resides on patients' physical and mental ability to answer questionnaires, which may have caused a selection bias.

- The patients' subjective reports of any harm were accounted for as occurrence of a complication and subsequently were not evaluated nor graded by the healthcare staff.

\section{INTRODUCTION}

Assessment of quality of healthcare can be taken from two perspectives: that of the healthcare provider and that of the patient. Traditional outcome measures such as morbidity and mortality statistics are essential, but they tend to overlook the patient's perspective of healthcare. This has recently been recognised, and the patient experience measures are becoming increasingly important when assessing the quality of hospital organisations and treatment outcomes. ${ }^{1}$ Indeed, patient experience is considered to be one of the three pillars of quality in healthcare alongside clinical effectiveness and patient safety. ${ }^{23}$

Individual patient characteristics, especially age, have been proposed to influence the perception of the received care. ${ }^{45}$ However, when the association between satisfaction 
ratings and other patient characteristics such as age, education, gender, ethnic origin and language difficulties have been studied, the results have been mixed. ${ }^{6}$

Patient experience seems to mostly associate with communication between healthcare providers and the patient (ie, interpersonal skill), ${ }^{27}$ but several studies indicate that hospitals that perform well on patient experience surveys, also do better on clinical metrics. ${ }^{1389} \mathrm{In}$ fact, evidence indicates associations between patient experience, clinical effectiveness and patient safety that appear consistent across a range of disease areas, study designs and settings. ${ }^{3}$ A patient's experience and perception of care during their surgical admission can impact their treatment, recovery and follow-up. ${ }^{38}$ Provision of good information and emotional support have been associated with better recovery from surgery and heart attacks. ${ }^{3} 10$ This is influential for the final surgical outcome, since more than $30 \%$ of postoperative complications occur within 30 days after hospital discharge. ${ }^{11}$

The objective of this study is to examine if patientrelated factors are associated with patient-evaluated quality of care in surgery. To examine if there is an association with postoperative complications and patientevaluated low quality of care.

\section{METHODS}

\section{Design and setting}

This was a correlation cross-sectional study added with a phone call interview at 30 days postoperatively to examine complications. The study population consisted of 436 adult patients undergoing surgery at a central hospital in Southwestern Finland between 18 April 2016 and 31 January 2017, who consented in participating in the study. Vacation period (21 June 2016 to 14 August 2016) was excluded. The central hospital serves a population of 230 000, with ca. 8000 operations performed yearly. During the study period, 1600 elective operations were performed within the three participating units. Ambulatory, paediatric and memory disorder patients were excluded. Ambulatory surgery concludes over half of the operations, so the potential number of patients included in the study was less than 800 operations. Of these, a sample of 436 consecutive consenting and eligible patients was achieved.

\section{Questionnaire and measurements}

A structured instrument, Good Nursing Care Scale for Patients (GNCS-P) was used to study the perceived quality of care. The GNCS has been tested and evaluated in multiple studies. ${ }^{1112}$

Prior to consenting the participants were informed about the scope of the study. The GNCS-P consists of seven content categories and 39 items measuring quality of care according to the Likert scale ( $1=$ strongly disagree, $4=$ strongly agree). Content categories of the instrument include staff characteristics (5 items), care-related activities (6 items), preconditions for care (5 items), environment (5 items), progress of nursing process $(6$ items), support of patients' empowerment strategies (7 items) and co-operation with relatives (6 items).

The GNCS-P questionnaire includes 10 questions on education, living and working status, numbers of visits to the hospital and commitment to treatment. Additional data, including demographic factors and factors affecting overall health (Charlson Comorbidity Index, ${ }^{13}$ MET (metabolic equivalent of task) Index,${ }^{14}$ body mass index, nutritional status, smoking and alcohol intake) as well as codes on diagnosis and procedure were collected from the electronic patient records after the surgical procedure (table 1).

\section{Data collection}

The GNCS-P was administered to 436 adult consenting eligible patients admitted for general surgery by a research assistant. The patients returned it anonymously at the time of hospital discharge. The study sample consisted of 378 patients who completed at least half of the questions for each sum variable. In the questionnaires, there were some uneven questions left unanswered, and due to anonymous setting, it was impossible to track the patients and ask why some questions were left unanswered.

A research assistant interviewed the patients by phone 30 days after the operation. The calls were not recorded. The patients were asked to report any postdischarge problems, and to describe or categorise the complication as wound complications (redness, swelling, rupture, secretion, infection), excessive pain, fever, permanent disadvantage or other problems.

Of the 378 patients, 323 answered the follow-up telephone call $(85 \%)$. All the patients that had left the questionnaire were given a phone call. The ones that answered the call were thus randomly selected from the ones returning the questionnaire, and the result represents the study sample.

\section{Data analysis}

Data were coded and analysed statistically by a trained statistician (PP) using SAS V.9.3 software (SAS Institute). Descriptive statistics, such as frequencies and percentages, means and SDs, were used to describe the variables. Quality was classified into two categories: (1) fair quality (sum score 1.0-3.0) and (2) high or very high quality (sum score 3.1-4.0).

Univariate associations between characteristics of patients and classified quality categories were examined by $\chi^{2}$ test. In case of too small expected frequencies, Fisher's exact test was used. Logistic regression analysis was used to find independent characteristics associated with quality categories. Differences in quality of care between those with and without reported complications were tested using Student's t-test. Due to skewed distributions, the results were checked using non-parametric methods. P values less than 0.05 were considered statistically significant. 
Table 1 Patient-related factors and overall quality of care evaluated by surgical patients $(n=378)$

\begin{tabular}{|c|c|c|c|c|c|c|c|}
\hline & \multirow[b]{2}{*}{$\mathbf{n}$} & \multirow[b]{2}{*}{$\%$} & \multicolumn{2}{|c|}{$\begin{array}{l}\text { Fair quality of care } \\
(n=34)\end{array}$} & \multicolumn{2}{|c|}{$\begin{array}{l}\text { High or very high quality } \\
\text { of care }(n=344)\end{array}$} & \multirow{2}{*}{ P value } \\
\hline & & & $\mathbf{n}$ & $\%$ & $n$ & $\%$ & \\
\hline Gender & & & & & & & 0.3262 \\
\hline Male & 186 & 49 & 14 & 7.5 & 172 & 92.5 & \\
\hline Female & 192 & 51 & 20 & 10.4 & 172 & 89.6 & \\
\hline Type of accommodation & & & & & & & 0.0088 \\
\hline Lives alone & 92 & 25 & 14 & 15.2 & 78 & 84.8 & \\
\hline Lives with another person & 281 & 75 & 18 & 6.4 & 263 & 93.6 & \\
\hline Admission to hospital & & & & & & & 0.1067 \\
\hline Elective & 306 & 81 & 24 & 7.8 & 282 & 92.2 & \\
\hline Emergency & 72 & 19 & 10 & 13.9 & 62 & 86.1 & \\
\hline $\begin{array}{l}\text { Would have sought treatment elsewhere if it had } \\
\text { been possible }\end{array}$ & & & & & & & 0.0114 \\
\hline Yes & 20 & 5 & 5 & 25.0 & 15 & 75 & \\
\hline No & 352 & 95 & 29 & 8.2 & 323 & 91.8 & \\
\hline State of health compared with normal & & & & & & & 0.0047 \\
\hline Excellent or good & 179 & 48 & 8 & 4.5 & 171 & 95.5 & \\
\hline Moderate or poor & 196 & 52 & 25 & 12.8 & 171 & 87.2 & \\
\hline Charlson Index & & & & & & & 0.8263 \\
\hline $0-2$ & 263 & 89 & 21 & 8.0 & 242 & 92.0 & \\
\hline 3- & 33 & 11 & 3 & 9.1 & 30 & 90.9 & \\
\hline MET Index (physical activity) & & & & & & & 0.2114 \\
\hline Needs assistance & 11 & 4 & 2 & 18.2 & 9 & 81.8 & \\
\hline Does not need assistance & 298 & 96 & 23 & 7.7 & 275 & 92.3 & \\
\hline Procedure & & & & & & & 0.2706 \\
\hline Orthopaedic surgery & 155 & 41 & 11 & 10.4 & 144 & 92.9 & \\
\hline Other & 221 & 59 & 23 & 7.1 & 198 & 89.6 & \\
\hline
\end{tabular}

$P$ values of significance $(<0.1)$ are marked in bold.

\section{Patient and public involvement}

Patients or the public were not involved in the design, or conduct, or reporting, or dissemination plans of our research.

\section{RESULTS}

\section{Characteristics of the patients}

Both genders were evenly distributed in the study population: $49 \%$ of the study population $(\mathrm{n}=378)$ were male (table 1). The mean age was 60.4 years (SD 15.1, range 19-88). Patients living alone accounted for $25 \%$ of the patients, and $52 \%$ of all patients reported their state of health as moderate or poor. Most of the patients were scheduled for elective surgery $(81 \%)$, and only $5 \%$ of the patients would have sought treatment elsewhere if possible. There were $41 \%$ orthopaedic and $59 \%$ general surgery patients (gi-, vascular, urologic and plastic surgery). The Charlson Indices were low (0-2) in 89\% of patients and only $4 \%$ needed assistance in their daily living, which indicates that the number and severity of comorbidities were low (table 1).

The association with patient-related factors and the quality of care evaluated by surgical patients

The lowest overall quality of care rate was assessed by patients living alone $(\mathrm{p}=0.0088)$, those who would have sought treatment elsewhere if it had been possible $(\mathrm{p}=0.0114)$ and by patients who evaluated their state of health moderate or poor $(\mathrm{p}=0.0047)$. After logistic regression analysis, the first two remained statistically significant (living alone $\mathrm{p}=0.0259$, state of health $\mathrm{p}=0.0149$ ).

\section{The relationship between the perceived quality of care and} postoperative complications

There were altogether 85 patients with reported postoperative complications (26\%) (table 2). These were mainly related to the wound or excessive pain, and therefor seen as minor complications. The overall quality of care was 
Table 2 Number and classification of reported postdischarge complications (85 patients)

\begin{tabular}{lr}
\hline Reported complications (85 patients, 26\%) & $\mathbf{n}^{*}$ \\
\hline Fever & 4 \\
Wound infection: superficial & 11 \\
Wound infection: deep & 16 \\
Wound dehiscence & 13 \\
Excessive pain & 22 \\
Gastrointestinal problems (nausea, diarrhoea) & 7 \\
Insomnia, pain, anxiety & 7 \\
Urinary problems & 4 \\
Other wound problem & 13 \\
Other & 11 \\
\hline
\end{tabular}

*The patient may have reported more than one complication.

evaluated high or very high by $91 \%$ of the patients (mean 3.58, SD 0.37, range 2.17-4.0) (table 3).

Postoperative complications were reported more often by patients who had reported lower overall quality of care $(\mathrm{p}=0.0105)$ (table 3$)$. Patients who reported postoperative complications, evaluated quality of care lower in categories 'care-related activities' $(\mathrm{p}=0.0126)$, 'progress of nursing process' $(\mathrm{p}=0.0012)$ and 'support of patients' empowerment strategies' $(\mathrm{p}=0.0115)$ (table 3$)$.

\section{DISCUSSION}

In this study, the focus was to examine surgical patients' evaluation of quality of care at discharge, its association with patient-related factors and patient-reported postdischarge complications. The patient perception on the quality of care was evaluated with distinctive questions on both communication and technical quality of care at the ward (GNCS-P). According to this article, no patient demographic nor health characteristics (age, education, gender, comorbidities) showed any difference in the rate of perceived quality. The only differences arose with living condition (the patients living alone evaluated the quality of care lower), estimation of overall health: those who estimated their state of overall health moderate or poor, also reported lower quality of care; and preconceptions (patients who would have sought treatment elsewhere if it had been possible estimated lower quality of care).

In the literature, the association between satisfaction ratings and demographic patient characteristics have been studied and led to mixed results. ${ }^{6}$ The major determinants of patient satisfaction with care have shown to be trust, physical comfort, emotional support and respect for patient preferences-that is, interpersonal skills of the healthcare staff. ${ }^{2715}$ Shared information and patient participation (ie, healthcare staff communication skills) have been associated with perceived quality of care, and pain and psychological distress have been associated with satisfaction rates. ${ }^{3} 1016-18$ In the current study, the factors associated with lower perceived quality of care by the patients living alone or evaluating their state of health poor may reflect more the psychological distress, pain or emotional needs of the patients and thus the quality of the communication and non-technical skills (NTS) of the healthcare staff. Patient satisfaction can be seen as an example of perception of quality of care but may be more influenced by patient expectations. ${ }^{5}{ }^{18}$ In this work, the patients who would have sought treatment elsewhere if it had been possible also evaluated the quality of care lower, which may reflect expectations or preconceptions.

\section{Complications and perceived quality of care}

In this study, most patients evaluated the overall quality to be high or very high. The patients reporting having complications at 30-day postdischarge evaluated lower overall quality already at discharge, and lower quality specifically in categories 'care-related activities', 'progress of nursing process' and 'support of patients' empowerment strategies'. As such, the result was seen in both technical care (care-related activities and progress of nursing

Table 3 Quality of care evaluated by surgical patients and patient-reported postoperative complications ( $n=323$ )

\begin{tabular}{llll}
$\begin{array}{l}\text { Patients with postoperative } \\
\text { complications }(\mathbf{n = 8 5})\end{array}$ & $\begin{array}{l}\text { Patients without postoperative } \\
\text { complications (n=238) }\end{array}$ & \\
\cline { 1 - 2 } Evaluated quality/mean (SD) & & Evaluated quality/mean (SD) & P value \\
\hline $3.49(0.42)$ & $3.63(0.35)$ & $\mathbf{0 . 0 1 0 5}$ \\
$3.70(0.50)$ & $3.81(0.33)$ & $\mathbf{0 . 0 6 2 1}$ \\
$3.55(0.53)$ & $3.70(0.41)$ & $\mathbf{0 . 0 2 0 3}$ \\
$3.57(0.50)$ & $3.69(0.39)$ & $\mathbf{0 . 0 5 2 9}$ \\
$3.79(0.30)$ & $3.86(0.26)$ & $\mathbf{0 . 0 6 1 7}$ \\
$3.45(0.52)$ & $3.65(0.43)$ & $\mathbf{0 . 0 0 1 6}$ \\
$3.43(0.59)$ & $3.57(0.48)$ & $\mathbf{0 . 0 6 3 0}$ \\
$2.72(0.94)$ & $2.92(0.92)$ & 0.1778
\end{tabular}

Quality categories

Total quality of care

Staff characteristics

Care-related activities

Preconditions for care

Environment

Progress of nursing process

Support of patients' empowerment strategies

Co-operation with relatives

$2.72(0.94)$

$2.92(0.92)$

Scale/good quality: 4=strongly agree, $1=$ strongly disagree.

$P$ values of significance $(<0.1)$ are marked in bold. 
process) as well as communication and interpersonal skills (support of patients' empowerment strategies). In this study, the perceived quality of care in healthcare staff communication skills and technical care had an association with reported postoperative complications.

There are several studies that demonstrate a significant association between patient satisfaction scores and objective measures of surgical quality. ${ }^{819-22}$ Technical, professional or system process quality deficiencies may be reflected by patients' low evaluation on the quality care categories. Patient-reported low quality has been associated with the presence of adverse events and medical errors ${ }^{21}$ readmissions within 30 days after discharge, ${ }^{8}$ and methicillin-resistant Staphylococcus aureus infection levels. $^{22}$

\section{Healthcare staff non-technical skills associated with perception of quality of care}

In this study, lower estimated quality in 'support of patients' empowerment strategies' was associated with reported complication rates. Healthcare staff empathy, NTS and communication skills have been associated as well with a high perception of quality as with better treatment outcomes. Patients show better treatment adherence and greater satisfaction with more empathetic doctors, while physicians' communication skills are associated with reduced risk of malpractice claims. ${ }^{23} 24$ In a study by Rakel et al, clinician empathy, as perceived by patients with common cold, predicted subsequent duration and severity of illness and was associated with immune system changes. ${ }^{25}$ Patient feedback reflects a patient's unique experience of healthcare and can offer insights into hospital quality that would be unseen from other perspectives-such as the way a treatment, process or interaction has made them feel and, subsequently, behave. ${ }^{326}$ This can even be seen in medical or surgical care outcomes as in this study.

Healthcare staff NTS may play even a bigger role in the future with more technology and complex healthcare settings. In Japan, a 3-year retrospective review of fatal medical accidents found roughly half to be due to failures of NTS, most often related to situational awareness, teamwork and decision-making. ${ }^{27} 28$ In this respect, patient feedback can provide an early warning system for safety issues as patient perception of poor healthcare staff interpersonal communication is associated with elevated adverse event rates. ${ }^{1-3}$ This aspect will be worth some future research.

In the end, effort needs to be put at the work environment so that healthcare staff can provide the best possible quality of care: staff feedback has been associated with patient-reported experience ${ }^{22}$ From the organisational view, 'psychological safety' at healthcare units predict engagement in quality improvement work and lead to better performing healthcare teams. ${ }^{29}$ According to a recent article, physician burnout has the tendency to put patient care at risk. ${ }^{30}$ This has become a global problem and concerns all healthcare staff. Many theories of physician burnout suggest that doctors no longer feel connected with the healthcare system but feel the loss of autonomy and that the solution would be patient-centred health systems that can maintain and support physicians' sense of purpose.$^{30}$ Thus, patient-reported quality, evaluated by good instruments, may reflect the core function of the healthcare system (patient-centeredness, staff performance and motivation) and give a prediction to other outcome measures. This can be considered as the key area for future research.

\section{Strengths and limitations}

This study has some strengths and limitations related to data, instruments and data collection. The sample involved one public central hospital in Western Finland and the inclusion criteria for patients' physical and mental ability to answer the questionnaires may have caused a selection bias.

Postdischarge complications were reported by the patients on the phone 30 days postoperatively. Patients' subjective reports of any harm (mainly wound problems, gastrointestinal problems, psychological problems) were accounted for as occurrence of a complication and subsequently, they were not evaluated nor graded by the healthcare staff.

The response rate to the follow-up telephone call was quite high (323 out of the 378 patients that completed the questionnaire, $85 \%$ ). The limitation is that we cannot know all the reasons why 55 patients did not answer the call. It can be due to human factors (ie, not all patients answer their telephone from an unknown number). However, the reason can also be the patient's deteriorating health or even death. This would naturally affect the results of the study. The strength of the study resides in different disciplines of surgical patients during a long period (8 months). The study population was demographically and geographically confined and the variability in quality evaluation was rather low. Therefor we consider the data to be representative. The quality survey instrument (GNCS-P) has been validated in several studies. ${ }^{11} 12$ It focuses on the quality of nursing and overall care at the unit.

\section{CONCLUSION}

Patient demographic factors do not seem to influence the perceptions of the quality of care. Instead, subjective state of health and living conditions may have an influence on the patient experience of quality of care. The perceived quality of care in healthcare staff communication skills may have an association with reported postoperative complications. There is need for future research as a longitudinal study considering perceived quality and objectively measured complications. Postoperative complications and quality of life could be measured by mobile or technical device with specific questionnaires. There is room for future research in this field. 
Twitter Jaana-Maija Koivisto @JaanaMai

Acknowledgements Pauli Puukka, MSocSc participated in data analysis and technical editing of the manuscript. Research nurse Katri Kivinen, RN collected data and provided care for study patients. The authors want to thank the surgical nurses in Satakunta Hospital, that worked as patient advisers in this study.

Contributors EH has made substantial contributions to the design of the work as well as the acquisition, analysis and interpretation of data for the work. IHS, J-MK and AK have made substantial contributions for the analysis and interpretation of data for the work. All authors have participated in drafting the work or revising it critically for important intellectual content and in the final approval of the version to be published. All authors have an agreement to be accountable for all aspects of the work in ensuring that questions related to the accuracy or integrity of any part of the work are appropriately investigated and resolved.

Funding This work was supported by The Finnish Cultural Foundation/Satakunta Regional Fund year 2017.

Competing interests None declared.

Patient and public involvement Patients and/or the public were not involved in the design, or conduct, or reporting, or dissemination plans of this research.

Patient consent for publication Not required.

Ethics approval The Ethical approval for this study was obtained from the Ethics Committee of the Higher Education Institution of Satakunta in 19 February 2016.

Provenance and peer review Not commissioned; externally peer reviewed.

Data availability statement № data are available. No data are available due to the limited Ethical approval from the Ethical Committee in 2016.

Open access This is an open access article distributed in accordance with the Creative Commons Attribution Non Commercial (CC BY-NC 4.0) license, which permits others to distribute, remix, adapt, build upon this work non-commercially, and license their derivative works on different terms, provided the original work is properly cited, appropriate credit is given, any changes made indicated, and the use is non-commercial. See: http://creativecommons.org/licenses/by-nc/4.0/.

ORCID iD

Ira Helena Saarinen http://orcid.org/0000-0001-8631-2897

\section{REFERENCES}

1 Luxford K. What does the patient know about quality? Int J Qual Health Care 2012;24:439-40.

2 O'Hara JK, Reynolds C, Moore S, et al. What can patients tell us about the quality and safety of hospital care? findings from a UK multicentre survey study. BMJ Qual Saf 2018;27:673-82.

3 Doyle C, Lennox L, Bell D. A systematic review of evidence on the links between patient experience and clinical safety and effectiveness. BMJ Open 2013;3:e001570.

4 Ware JE, Snyder MK, Wright WR, et al. Defining and measuring patient satisfaction with medical care. Eval Program Plann 1983:6:247-63.

5 Sofaer S, Firminger K. Patient perceptions of the quality of health services. Annu Rev Public Health 2005;26:513-59.

6 Hall JA, Dornan MC. Patient sociodemographic characteristics as predictors of satisfaction with medical care: a meta-analysis. Soc Sci Med 1990;30:811-8.

7 Cheng S-H, Yang M-C, Chiang T-L. Patient satisfaction with and recommendation of a hospital: effects of interpersonal and technical aspects of hospital care. Int J Qual Health Care 2003;15:345-55.
8 Lobo Prabhu K, Cleghorn MC, Elnahas A, et al. Is quality important to our patients? The relationship between surgical outcomes and patient satisfaction. BMJ Qual Saf 2018;27:48-52.

9 Sacks GD, Lawson EH, Dawes AJ, et al. Relationship between hospital performance on a patient satisfaction survey and surgical quality. JAMA Surg 2015;150:858-64.

10 Mumford E, Schlesinger HJ, Glass GV. The effect of psychological intervention on recovery from surgery and heart attacks: an analysis of the literature. Am J Public Health 1982;72:141-51.

11 Koivisto JM, Saarinen I, Kaipia A, et al. Patient education in relation to informational needs and postoperative complications in surgical patients. Int J Qual Health Care2019.

12 Rehnström L, Christensson L, Leino-Kilpi H, et al. Adaptation and psychometric evaluation of the Swedish version of the good nursing care scale for patients. Scand J Caring Sci 2003;17:308-14.

13 Charlson ME, Pompei P, Ales KL, et al. A new method of classifying prognostic comorbidity in longitudinal studies: development and validation. J Chronic Dis 1987;40:373-83.

14 Ainsworth BE, Haskell WL, Leon AS, et al. Compendium of physical activities: classification of energy costs of human physical activities. Med Sci Sports Exerc 1993;25:71-80.

15 Jenkinson C, Coulter A, Bruster S, et al. Patients' experiences and satisfaction with health care: results of a questionnaire study of specific aspects of care. Qual Saf Health Care 2002;11:335-9.

16 Weingart SN, Zhu J, Chiappetta L, et al. Hospitalized patients' participation and its impact on quality of care and patient safety. Int $J$ Qual Health Care 2011;23:269-77.

17 Gröndahl W, Muurinen H, Katajisto J, et al. Perceived quality of nursing care and patient education: a cross-sectional study of hospitalised surgical patients in Finland. BMJ Open 2019;9:e023108.

18 Sitzia J, Wood N. Patient satisfaction: a review of issues and concepts. Soc Sci Med 1997;45:1829-43.

19 Black N, Varaganum M, Hutchings A. Relationship between patient reported experience (PREMs) and patient reported outcomes (PROMs) in elective surgery. BMJ Qual Saf 2014;23:534-42.

20 Kennedy GD, Tevis SE, Kent KC. Is there a relationship between patient satisfaction and favorable outcomes? Ann Surg 2014;260:592-600.

21 Taylor BB, Marcantonio ER, Pagovich O, et al. Do medical inpatients who report poor service quality experience more adverse events and medical errors? Med Care 2008;46:224-8.

22 Raleigh VS, Hussey D, Seccombe I, et al. Do associations between staff and inpatient feedback have the potential for improving patient experience? an analysis of surveys in NHS acute trusts in England. Qual Saf Health Care 2009;18:347-54.

23 Mercer SW, Reynolds WJ. Empathy and quality of care. Br J Gen Pract 2002;52:S9-12.

24 Levinson W, Roter DL, Mullooly JP, et al. Physician-patient communication. The relationship with malpractice claims among primary care physicians and surgeons. JAMA 1997;277:553-9.

25 Rakel DP, Hoeft TJ, Barrett BP, et al. Practitioner empathy and the duration of the common cold. Fam Med 2009;41:494-501.

26 Chow A, Mayer EK, Darzi AW, et al. Patient-reported outcome measures: the importance of patient satisfaction in surgery. Surgery 2009;146:435-43.

27 Uramatsu M, Fujisawa Y, Mizuno S, et al. Do failures in non-technica skills contribute to fatal medical accidents in Japan? A review of the 2010-2013 national accident reports. BMJ Open 2017:7:e013678.

28 Johnson AP, Aggarwal R. Assessment of non-technical skills: why aren't we there yet? BMJ Qual Saf 2019;28:606-8.

29 Nembhard IM, Edmondson AC. Making it safe: the effects of leader inclusiveness and professional status on psychological safety and improvement efforts in health care teams. J Organ Behav 2006;27:941-66.

30 Physician burnout: the need to rehumanize health systems. Lancet 2019;11. 